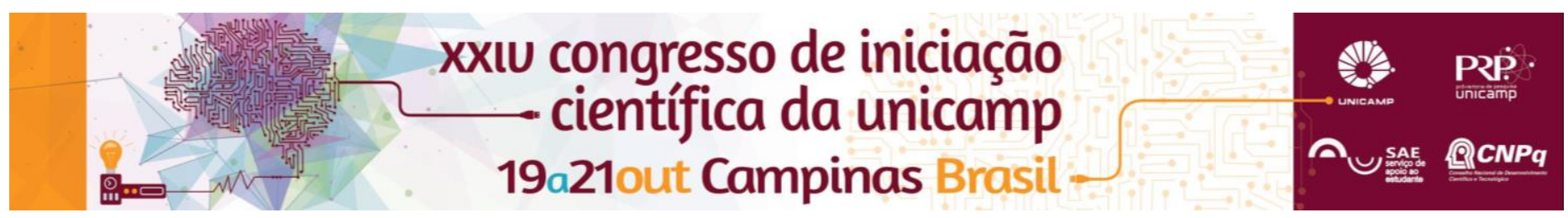

\title{
Trajetória profissional de doutores: a inserção de engenheiros na indústria brasileira.
}

\author{
Erik Alves Carantino*, Adriana Bin.
}

\section{Resumo}

O projeto busca discutir a empregabilidade de doutores egressos em áreas relacionadas à ciência e tecnologia na indústria brasileira, analisando suas motivações e expectativas, bem como as expectativas e motivações da indústria, para a construção de um panorama que explique as preferências por esta carreira em detrimento de outras carreiras que são tradicionalmente seguidas por doutores, especialmente a carreira acadêmica.

\section{Palavras-chave: \\ empregabilidade, doutores, indústria.}

\section{Introdução}

Com o declínio da empregabilidade na academia, é possível notar uma tendência em uma série de contextos internacionais que abrangem a empregabilidade de doutores em setores não acadêmicos. No Brasil, a discussão do tema é recente. Sendo assim, o presente projeto busca contribuir com a literatura a respeito da empregabilidade de doutores em engenharia na indústria brasileira. A discussão da empregabilidade de doutores abrange as motivações e expectativas dos doutores e também as motivações e expectativas das empresas para contratarem estes profissionais. O trabalho busca contribuir com a discussão conceitual do tema através de resultados empíricos, obtidos a partir de um estudo de caso que contempla os doutores egressos em Engenharia Elétrica da Universidade Estadual de Campinas. Serão levantados dados primários e secundários, que abrangerão aspectos como satisfação na carreira, contribuição em pesquisa e desenvolvimento e aspectos salariais. Espera-se que estes dados forneçam subsídios para a distinção dos principais obstáculos e oportunidades para inserção de doutores na indústria brasileira.

\section{Resultados e Discussão}

A metodologia do trabalho consiste em duas frentes: revisão bibliográfica e estudo de caso. Em relação à primeira vertente, foi possível notar que há uma escassez de material sobre a empregabilidade de doutores no cenário brasileiro. Portanto, boa parte da revisão da literatura se concentrou na discussão de cenários internacionais, analisando a motivação e a expectativa de doutores estrangeiros. Neste cenário, a segunda vertente pretende contribuir com a discussão do caso brasileiro. Os dados empíricos que servirão como fundamento para a discussão de possíveis conclusões serão obtidos através de um questionário online feito com os doutores egressos no curso de Engenharia Elétrica da UNICAMP.

Até o momento, o principal motivo pelo qual doutores em engenharia optaram por uma carreira não acadêmica, consiste no forte interesse por pesquisas voltadas a um produto e ao mercado. Este interesse por uma atuação diferente do âmbito acadêmico está em concordância com o aspecto levantado por Lee et al. (2010).

Por semelhante modo, a pesquisa aponta que uma das motivações para que empresas contratem doutores consiste na possibilidade de estimular inovação em suas pesquisas, apontada pela grande maioria da amostra entrevistada. Este resultado está em concordância com o aspecto apontado por Garcia-Quevedo et al. (2012) e Zellner (2003 apud. HERRERA, NIETO, 2013).

Outro aspecto apontado pela pesquisa como motivação para a contratação de doutores por parte das empresas é a assimilação de conhecimento técnico complexo. De fato, Herrera e Nieto (2013) e também Cohen e Levinthal (1989) já apontaram a importância destes profissionais que contribuem com a habilidade de explorar informações técnicas.

\section{Conclusões}

O trabalho está obtendo informações relevantes sobre o cenário da empregabilidade de doutores em engenharia em carreiras não acadêmicas. Através de uma revisão bibliográfica robusta, é possível comparar os resultados da pesquisa com cenários já pesquisados anteriormente e traçar paralelos entre os estudos.

Desta forma, o projeto contribui com a discussão do cenário brasileiro em relação ao tema proposto, diminuindo a lacuna na literatura e aproximando-se da discussão internacional sobre a empregabilidade de doutores.

\section{Agradecimentos}

Agradeço à minha orientadora, Prof ${ }^{a}$. Dr ${ }^{\mathrm{a}}$. Adriana Bin pelo apoio e orientação durante o desenvolvimento do estudo, à Faculdade de Ciências Aplicadas da Universidade Estadual de Campinas, por ser minha instituição de ensino e ao Conselho Nacional de Desenvolvimento Científico e Tecnológico (CNPq) por garantir os recursos necessários para o desenvolvimento da pesquisa.

\section{Referências Bibliográficas}

${ }^{1}$ LEE, Hsing-fen; MIOZZO, Marcela; LAREDO, Philippe. Career patterns and competences of PhDs in science and engineering in the knowledge economy: The case of graduates from a UK research-based university. Research Policy, v. 39, n. 7, p. 869-881, 2010.

${ }^{2}$ GARCIA-QUEVEDO, J; MAS-VERDÚ, F; POLO-OTERO, J. Which firms want PhDs? An analysis of the determinants of the demand. Higher Education, v. 63 , p. $607-620,2012$.

3 ZELLNER, C apud. HERRERA, L; NIETO, M. The economic effects of basic research: Evidence for embodied knowledge transfer via scientists' migration. Research Policy, 32(10), 1881-1895, 2003.

${ }^{4}$ HERRERA, L; NIETO, M. Recruitment of PhD Researchers by Firms. 35th DRUID Celebration Conference, Barcelona, 2013.

${ }^{5}$ COHEN, Wesley M.; LEVINTHAL, Daniel A. Innovation and Learning: The Two Faces of R\&D. The Economic Journal, v. 99, n. 397, p. 569-596, 1989. 